\title{
Interlocuções entre a avaliação da aprendizagem e Representações Sociais: à docência em foco
}

\author{
Interlocuciones entre la evaluación del aprendizaje y las Representaciones \\ Sociales: la docencia en foco
}

\author{
Interlocutions between the evaluation of learning and Social \\ Representations: to teaching in focus
}

\author{
Veronica Cunha Barcellos ${ }^{1}$
}

Daniele Simões Borges ${ }^{2}$

\begin{abstract}
Resumo
Os estudos acerca da avaliação da educacional têm contemplado diversos aspectos e fatores que incidem na atividade docente. Buscando contribuir com as discussões desse campo do conhecimento o presente artigo tem por objetivo problematizar as Representações Sociais a respeito da avaliação na educação básica. O texto referese, a um estudo de caráter bibliográfico-documental tendo como base teórica a Teoria das Representações Sociais de Moscovici. Assim, compreendo que as $\mathrm{RS}^{3}$ são modos involuntários de compreender um determinado fenômeno ou uma determinada prática existencial, individual ou coletiva, que se apresentam por meio de falas cotidianas, crenças e posicionamentos, ligados ao passado, ao presente ou ao futuro. Esse processo subjetivo ajudará os docentes a encontrarem evidências que alarguem as fronteiras da avaliação em sua trajetória docente e que, muitas vezes foram reforçadas, na sua formação acadêmica. É importante [re]pensar quais são as perspectivas teóricas de avaliação dos professores, potencializando a compreensão não pela via da fragmentação, mas da reintegração dos saberes, atribuindo outro sentido às representações estagnadas da avaliação. Assim, o processo avaliativo torna-se um dos temas mais importantes dos procedimentos pedagógicos, sendo percebido como um instrumento, de aperfeiçoamento da prática pedagógica, que contribui para a compreensão não só das dificuldades, mas também das conquistas, potencializando novas oportunidades de aprendizagem para todos.
\end{abstract}

Palavras-Chave: avaliação da aprendizagem; docência; professores; representação social;

\section{Resumen}

Los estudios sobre la evaluación educativa han contemplado diversos aspectos y factores que inciden en la actividad docente. Buscando contribuir con las discusiones de ese campo del conocimiento el presente artículo tiene por objetivo problematizar las Representaciones Sociales a respecto de la evaluación en la educación básica. El texto se refiere, a un estudio de carácter bibliográfico-documental teniendo como base teórica la Teoría de las Representaciones Sociales de Moscovici. Así, comprendo que las RS [1] son maneras involuntárias de comprender un determinado fenómeno o una determinada práctica existencial, individual o colectiva, que se presentan por medio de conversaciones cotidianas, creencias y posicionamientos, ligados al pasado, al presente o al futuro. Este proceso subjetivo ayudará a los docentes a encontrar evidencias que amplíen las fronteras de la evaluación en su trayectoria docente y que a menudo se han reforzado en su formación académica. Es importante reflexionar cuáles son las perspectivas teóricas de evaluación de los profesores, potenciando la comprensión no por la vía de la fragmentación, sino de la reintegración de los saberes, atribuyendo otro sentido a las representaciones estancadas de la evaluación. Así, el proceso de evaluación se convierte en uno de los temas más importantes de los procedimientos pedagógicos, siendo percibido como un instrumento, de perfeccionamiento de

\footnotetext{
${ }^{1}$ Mestranda em Educação; Universidade Federal do Rio Grande - FURG; Rio Grande, Rio Grande do Sul e Brasil; veronicacunhabarcellos@gmail.com

${ }^{2}$ Doutora em Educação em Ciências; Universidade Federal do Rio Grande - FURG; Rio Grande, Rio Grande do Sul e Brasil; daniele.uab@gmail.com

${ }^{3}$ Representações Sociais
} 
la práctica pedagógica, que contribuye a la comprensión no sólo de las dificultades, sino también de las conquistas, potenciando nuevas oportunidades de aprendizaje para todo el mundo.

Palabras clave: evaluación del aprendizaje; enseñanza; profesores; representación social;

\begin{abstract}
The studies about the evaluation of the educational have contemplated several aspects and factors that affect the teaching activity. In order to contribute to the discussions of this field of knowledge the present article aims to problematize the Social Representations regarding the evaluation in the basic education. The text refers to a bibliographical-documentary study based on the Theory of Social Representations of Moscovici. Thus, I understand that SRs are involuntary ways of understanding a certain phenomenon or a particular existential practice, individual or collective, that present themselves through everyday speech, beliefs and positions, linked to the past, the present or the future. This subjective process will help teachers to find evidence that extends the boundaries of evaluation in their teaching trajectory and which have often been reinforced in their academic training. It is important to [re] think about the theoretical perspectives of teacher evaluation, enhancing understanding not through fragmentation, but through the reintegration of knowledge, attributing a different meaning to stagnant representations of evaluation. Thus, the evaluation process becomes one of the most important topics of pedagogical procedures, perceived as an instrument, improvement of pedagogical practice, which contributes to the understanding not only of difficulties, but also of achievements, enhancing new learning opportunities for all.
\end{abstract}

Keywords: learning assessment; teaching; teachers; social representation;

\title{
1. Introdução
}

Neste texto almejamos tecer reflexões sobre a interlocução entre a teoria das Representações Sociais e seus desdobramentos quanto a pensamos juntamente com os processos de avaliação. Assim, buscando contribuir com as discussões desse campo do conhecimento o presente artigo tem por objetivo problematizar as Representações Sociais a respeito da avaliação na Educação Básica A avaliação da aprendizagem recebe grande valorização e destaque no atual contexto educacional, sendo alvo de inúmeras discussões no meio acadêmico. A sua importância é apontada por Ferreira (2002), ao afirmar que essa prática merece atenção especial, pois por meio dela o professor evidencia a aprendizagem do aluno em relação aos conhecimentos já assimilados e aqueles que necessitam ser retomados durante o processo de ensino-aprendizagem. Nessa mesma direção, Melchior (1994) ressalta que a avaliação tem também como função auxiliar o educando na sua autoavaliação, levandoo a compreender sobre seus erros e acertos, a partir de um pensamento conjunto, que possibilitará o autoconhecimento e a busca por novos caminhos de realização.

Outro ponto primordial sobre a importância da avaliação da aprendizagem tem relação com seus efeitos nos processos de ensinar e de aprender. Melchior (1994) afirma que muitos professores não têm entendimento sobre o conceito de avaliação e, desta forma, empregam terminologias inapropriadas, usando elementos que integram o processo avaliativo como se 
fosse a própria ação de avaliar, valorizando mais os instrumentos avaliativos do que os processos de ensino e de aprendizagem.

Desta forma, é importante ressaltar que, na maioria das vezes, segundo Tardif (2011), os conceitos que os professores apresentam em relação à avaliação, estão associados às experiências que antecederam a sua prática e ou também a fatos que aconteceram durante sua formação e influenciaram diretamente a sua ação docente: como as escolas em que estudaram enquanto alunos, sobre os professores que tiveram, sobre os cursos que fizeram questões culturais, etc.

Diante dessa constatação, entendemos que ainda é preciso esforços no campo da pesquisa para que sejam produzidas reflexões com relação à representação social de avaliação sobre a prática pedagógica dos professores. De acordo com entendimento de Neto e Aquino (2009), uma prática educativa centrada na construção do conhecimento por parte do aluno e na interdependência do processo ensino e aprendizagem está diretamente ligada à concepção que o professor tem de avaliação.

$\mathrm{Da}$ perspectiva da aprendizagem, a avaliação influencia diretamente $\mathrm{o}$ desenvolvimento do aluno. Por isso que avaliar segundo Silva (2002), não é somente constatar ou examinar, mas, sim analisar, interpretar, tomar decisões e reorganizar o ensino sempre com caráter contínuo. Acreditamos que resistir à cultura da avaliação que exclui, classifica, soma, rotula, é condição essencial de um projeto educativo que visa à aprendizagem dos educandos.

Compreendemos que é necessário que o professor, compreenda primeiro que uma escola apresenta uma realidade viva, que não se encontra pronta e acabada, ela é composta por indivíduos de pensamentos, crenças e visões diferentes. Ela é a expressão de atores sociais que nela atuam. A escola possui sua própria cultura, levando em conta a realidade a qual esta inserida. Lima (2008) destaca que as escolas não são apenas fruto de hetero-organização, mas carregam dentro de si o germe da auto-organização. Logo a escola, em toda a sua complexidade, torna-se um espaço de contradições e controvérsias, com vistas à constituição de saberes e conhecimentos colaborativos, imbricados e realimentados pela experiência da ação cotidiana fazendo com que os atores locais aprendam a usar suas capacidades estratégicas e sua autonomia em prol de um projeto com o qual se identifiquem.

Compreendemos, então, que a escola não é um lugar pronto e acabado e sim um espaço, segundo Gadotti (2012, p. 37) "propositor de um olhar sobre a práxis social do indivíduo que reconstitui ações individuais diferentes, reestruturando a própria ação social”. Portanto, segundo Zabala (1998) a formação docente permanente precisa envolver a 
compreensão sobre as experiências e contradições formativas dos sujeitos envolvidos no processo educacional, tanto pelo viés da prática pedagógica como das concepções teóricas que os compõe.

Então, podemos afirmar que os docentes possuem entendimentos, práticas, referências, vivências e modos de pensar o processo avaliativo, e que está construção de saberes, socialmente elaborado acerca da avaliação comporta atravessamentos, simbolismos e interações construídas coletivamente ao longo da sua trajetória.

\section{O que são as Representações Sociais?}

As representações sociais são teorias sobre os saberes populares e do senso comum, elaboradas e partilhadas coletivamente, com a finalidade de construir e interpretar a realidade vivencial dos indivíduos diante de uma comunidade e de suas relações coletivas. Segundo Moscovici (2004) elas centram-se em ideias sociais, políticas, culturais, artísticas ou cientificas onde desafiam um princípio ou uma ordem estabelecida que acabem por convencer um número suficiente de gente para poder se implantar com êxito em alguns casos e formarem pensamento majoritário.

Porém, antes de abordar sobre conceito de RS é necessário primeiro fazer um pequeno resgate histórico da passagem do século XIX para o XX. Sendo este último marcado por ideais revolucionários e por movimentos de libertação operária, surgindo então novos valores e concepções de mundo. Barreto (2005) coloca que para acompanhar essas mudanças algumas teorias foram reconstruídas, inclusive a da representação.

A palavra, representação origina-se do latim representare - "fazer presente" ou "apresentar de novo". Fazer presente alguém ou alguma coisa ausente, mesmo uma ideia, por intermédio da presença de um objeto (FALCON, 2000).

Para Jovchelovitch (1998) "representar" seria copiar ou reproduzir o social, espelhar o mundo. Segundo Bellini e Reis (2011, p. 149) “essa ideia influenciou, por longo tempo, as ciências sociais e a psicologia, dando a ilusão da coincidência perfeita entre o psíquico e o mundo".

Quando a Teoria das Representações surgiu, foi separada em dois níveis: o do fenômeno individual e o do coletivo, pois se acreditava que as leis que justificavam os fenômenos coletivos divergiam das que explicavam os fenômenos individuais (FARR, 1995). 
De acordo com Minayo (1995) os teóricos, Schutz, Weber, Durkheim e Marx que estudavam esta teoria na época, preocupavam-se apenas com o caráter coletivo das representações. Max Weber utilizou "Representação" associando-a a "ideia", "espírito", "concepção", "mentalidade" para, de forma particular, elaborar sua noção de "visão de mundo". Para Weber, a vida social - que consiste na conduta cotidiana dos indivíduos - é carregada de significação cultural. Essa significação provém da base material e das ideias, condicionando-se mutuamente (MINAYO, 1995 apud Bellini e Reis 2011).

Segundo Martini (2001, p.167) o teórico Durkheim associa o conceito de representação ao entendimento de Representações Coletivas, classificando-as como um "sistema de símbolos através do qual a sociedade se torna consciente de si mesma, representação significava a lei, a moral, os costumes, as instituições políticas, as práticas pedagógicas, todas as formas de vida coletiva", constituindo o que ele denominou de "consciência coletiva".

Para Moscovici (2001) Durkheim acreditava que as representações dominantes presentes na sociedade exercem uma grande pressão ao indivíduo. E é esta que pensa ou expressa os sentimentos dos sujeitos pertencentes a ela. Portanto as representações podem tanto conservar o estigma da realidade social, de onde surgem, como também podem ser independentes, reproduzindo-se e misturando-se, e apresentando outras representações.

Ou seja, as críticas de Moscovici (2001) à concepção durkheimiana apontam a falta de preocupação em se buscar a origem dos fenômenos sociais ou psíquicos, que a Representação Coletiva integra, como a ciência, a religião, a ideologia, dentre outras, bem como a ausência de dinâmica e uma grande rotatividade das representações, na teoria de Durkhein, não permitiu um estudo adequado das sociedades complexas e plurais dos sistemas que os indivíduos estão envolvidos (políticos, filosóficos, religiosos, entre outros).

Segundo Minayo (1995) o termo "senso comum" é utilizado por Schutz para tratar das Representações Sociais do cotidiano. Para Shultz, o senso comum envolve conjuntos de abstrações, formalizações e generalizações da mesma forma que o conhecimento científico. E que esses são fatos constituídos e interpretados no dia-a-dia. Para Bellini e Reis (2011, p. 145) essa existência cotidiana é dotada de significados e portadora de estruturas de relevância para os grupos sociais que vivem, pensam e agem em determinado contexto social.

Por fim, Minayo (1995) traz a concepção Marxista da interpretação das Representações Sociais, evidenciada em seu livro A Ideologia Alemã, onde Marx aponta como categoria chave das representações, a questão da consciência. Para ele as "representações, as ideias e os pensamentos são os conteúdos da consciência que, por sua vez, são determinadas pela base material" (MINAYO, 1995, p. 93). 
De acordo com Arruda (2002) a teoria das RS como conhecemos hoje surge com os estudos do psicólogo romeno Serge Moscovici, no final da década de 70, com alguns propósitos: operacionalizar o conceito da Representação Social; superar a teoria das representações coletivas defendida por Durkheim e para criticar os pressupostos positivistas, cognitivista, individualista e funcionalista da psicologia social americana. No decorrer do seu estudo, Moscovici recorreu a grandes teóricos, como Piaget, estudando o desenvolvimento do pensamento infantil. A Lévy-Bruhl, que chamava a atenção para a coerência dos sentimentos, raciocínios e movimentos da vida mental coletiva. Para ele os indivíduos sofriam influências da sociedade e, por isso, exprimiam sentimentos comuns, que ele chamou de representação. Em relação a Freud Moscovici, aprofundou seus estudos, sobretudo na paralisia histérica e no tratamento psíquico e na preocupação em mostrar como as representações passam do coletivo para o individual e como o social intervém na representação individual. E para operacionalizar o conceito da Representação Social e a ideia de construção do saber e do valor do saber prático o autor debruça-se na teoria de Vygotsky.

Diante disso, a teoria das RS possibilita a investigação sobre como se formam e como funcionam os sistemas de referência que utilizamos para classificar grupos e indivíduos, procurando interpretar os acontecimentos da realidade cotidiana.

De acordo com Moscovici (2001, p. 181) as $\mathrm{RS}^{4}$

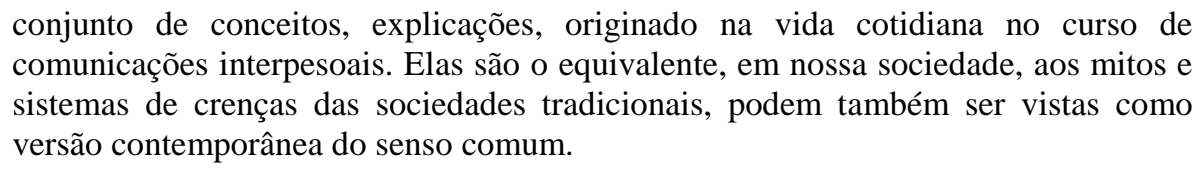

Portanto para Moscovici (2001), essas representações são dinâmicas, levam os indivíduos a produzir comportamentos e interações com o meio, ações que, sem dúvida, modificam ambos. Elas mudam de acordo com o tempo e espaço. Podem ter elementos comuns, mas estão alinhadas de formas diferenciadas.

As representações servem como estratégias para que nós possamos agir no nosso ambiente social, elas vão sendo compactuadas. A interpretação de um sujeito é a representação de uma representação, portanto uma representação pode ser um objeto físico ou mental.

Essa teoria aproxima-se da UTOPIA, por ser um conceito abrangente, amplo, complexo, que acompanha outros conceitos, atitudes, opiniões... A RS não substitui conceitos e sim incorpora outros. O elemento social é constitutivo, ele não determina a pessoa, mas a constitui, pois, o ser humano é essencialmente social.

\footnotetext{
${ }^{4}$ Representações Sociais
} 
Para Jodelet (1989, p. 36) as RS são uma forma de conhecimento socialmente elaborado e partilhado, tendo uma visão prática e concorrendo para a construção de uma realidade comum a um conjunto social. A RS possui elementos dinâmicos e explicativos, tanto na realidade social, física ou cultural, elas possuem uma dimensão histórica e transformadora, nelas estão presentes aspectos culturais cognitivos e valorativos: ideológicos (produção de ideia dos grupos, povos, relações que as pessoas mantêm em relação a determinados contextos). Estão sempre presentes nos objetos e sujeitos, são relacionais e, portanto sociais, interligados entre cognição, afeto e ação.

Assim sendo, o ato de representar não é um processo simples. Além da imagem, ele carrega sempre um sentido simbólico. Conforme Jodelet (2001) há quatro características fundamentais no ato de representar:

1) A representação social é sempre representação de alguma coisa (objeto) e de alguém (sujeito);

2). Tem caráter simbólico significante, é imagem e com isso pode alterar a sensação e a ideia, a percepção e o conceito;

3). Tem poder ativo e construtivo;

4). Possui um caráter autônomo e generativo.

Portanto para Jodelet (2001), a teoria das RS versa sobre a produção dos saberes sociais, concentrando-se na análise da construção e transformação de qualquer forma de conhecimento produzido no cotidiano e pertencente ao mundo social.

Para Moscovici (2001) a Teoria das Representações Sociais trata de alinhavar o pensamento social em sua dinâmica e sua diversidade e parte da inferência de que existem diferentes formas de conhecer e comunicar-se pautada por diferentes objetivos e formas. Representar um objeto, é, ao mesmo tempo, conferir-lhe o status de um signo, é conhecê-lo, tornando-o significante, ou seja, tornar familiar o não familiar.

Para Mazzottti (2008) as representações são construídas como opiniões, justificativas e julgamentos sobre o que acontece ao redor. Moscovici (2001, p. 26) afirma que é uma modalidade particular de conhecimento cuja função é a elaboração de comportamentos e a comunicação entre os indivíduos.

Ao preocupar-se com a dinâmica das interações sociais, a Teoria das Representações Sociais não concebe o sujeito em separado do objeto. Para Abric (1994, p. 12) o objeto se insere num contexto concebido pelo sujeito como prolongamento do seu comportamento.

Assim sendo, para Abric (1994) a representação, então, funciona como sistema sociocognitivo e como sistema contextualizado. Como sistema sociocognitivo, supõe um 
sujeito ativo que produz representações acerca de um determinado objeto. Tais representações, embora estejam submetidas às regras dos processos cognitivos, são determinadas inicialmente pelas condições sociais nas quais se elabora e se transmite uma representação.

Além disso, Moscovici (2001) ressalta que essas representações são partilhadas pelas pessoas, influenciando-as. Elas significam a circulação de todos os sistemas de classificações, todas as imagens e todas as descrições, mesmo as científicas. Para Abric (2000, p.28) "essas representações têm um papel fundamental na dinâmica das relações e nas práticas sociais e respondem a quatro funções que as sustentam”. Para Abric (2000) são elas:

1) Função de saber: permite compreender e explicar a realidade. Nesta função as RS consentem que os atores sociais conquistem os saberes práticos do senso comum em um quadro apreendido e compreensível, adequado ao seu funcionamento cognitivo e os valorativos.

2) Função identitária: definem a identidade e permitem a proteção da especificidade dos grupos. As representações têm por função situar os indivíduos e os grupos no campo social, permitindo a elaboração de uma identidade social e pessoal gratificante, compatível com o sistema de normas e de valores socialmente e historicamente determinados.

3) Função de orientação: onde as RS guiam os comportamentos e as práticas. A representação é prescritiva de comportamentos ou de práticas obrigatórias, definindo o que é lícito, tolerável ou inaceitável em um dado contexto social.

4) Função justificadora: as representações permitem, a princípio, a justificativa das tomadas de posição e dos comportamentos. Elas têm por função preservar e justificar a diferenciação social, e podem estereotipar as relações entre os grupos, contribuindo para a discriminação ou para a manutenção da distância social entre eles.

Assim para compreender o fenômeno de algumas Representações Sociais, é necessário responder o seguinte questionamento: Por que essas representações são criadas? A resposta é que a finalidade de todas as representações é tornar familiar algo não-familiar. Moscovici (2004) considera que o não-familiar são as idéias ou as ações que nos perturbam e nos causam tensão. Essa tensão entre o familiar e o não-familiar é sempre estabelecida em nossos universos consensuais, no entanto, o que nos é incomum, não-familiar é assimilado e pode modificar nossas crenças. Esse é o processo de re-apresentar o novo.

Portanto, a RS segundo Queiroz (2000) é um tipo de saber socialmente negociado ${ }^{5}$, contido no senso comum, que é um tipo de saber que se reproduz ou produz sem saber o porquê sem ter consciência. Para Jodelet (2001) essa forma especifica de conhecimento, o saber do

\footnotetext{
${ }^{5}$ Atribuem significados para representações o que representar melor aquilo está ausente e e quer representar
} 
senso comum, cujos conteúdos manifestam a produção de processos marcados socialmente e amplamente, designa uma forma de pensamento social, apresentando características especificas no plano da organização dos conteúdos, das operações mentais e da lógica. No entanto, nem sempre as representações do senso comum têm a ver com o nosso conhecimento dito cientifico, às vezes passam por lógicas muito diferenciadas. Outra dimensão citada por Queiroz (2000) é a dimensão do cotidiano, que permite ao indivíduo uma visão de mundo e o orienta nos projetos de ação e as estratégias que desenvolvem em seu meio social. A RS se enraíza na realidade social, histórica como também pode determinar a história, pois os indivíduos não só reproduzem determinadas representações (às vezes mecanicamente), como também as criticam.

Por que criamos as RS? Para tornar familiar o que não é familiar; tendemos a rejeitar o estranho, o diferente as novas informações sensações e percepções que nos trazem desconforto; ambos são eficazes e indispensáveis para a vida humana. Elas se inter-relacionam, se constroem mais frequentemente no universo consensual; RS conjunto de ideias que são dialogadas e construídas em determinadas comunidades e territórios. São formas simbólicas de produzir relações de poder e hierarquias, elas não são neutras, elas têm sua função na sociedade. As RS colocam os saberes do senso comum em uma categoria cientifica. Valorizando este conhecimento popular, tornando possível e relevante sua investigação. Permitindo redescobrir a complexidade da vida humana. E é possível mudar essas representações? Para Costa (1999) sim, já que as RS são pontes entre o mundo individual e o social, ou seja, elas não são somente externas ao individuo, elas também são construídas e adquiridas tendo como resultado um caráter dinâmico, portanto elas sofrem mudanças ao longo do tempo. Sendo assim, as representações apresentam um universo interno e externo ao sujeito e estes se complementam.

Assim, a RS tem relação com a opinião pública. Porém, a Representação Social não é mera opinião, vai além dela, pois está relacionada à avaliação do objeto, aos sentimentos associados a ele e isso enquanto característica produzida e compartilhada por um grupo. Entretanto, as proposições, reações ou avaliações estão organizadas de maneira muito diversa segundo as classes, as culturas ou grupos, e constituem tantos universos de opinião quantas classes, culturas ou grupos existentes (MOSCOVICI, 2001). Segundo o autor, estas proposições, reações e avaliações estão organizadas de acordo com a cultura e a formação social de cada grupo e, a partir disto, lança a ideia de que cada contexto social está dividido em três dimensões: a atitude, a informação e o campo de representações ou a imagem.

Em suma, para Moscovici (2001), a teoria da RS é uma modalidade particular de comportamento, que visa explicar a realidade social, fenômenos, mitos, conceitos, espaços, 
crenças e ideias que permitam evocar um dado acontecimento, pessoa ou objeto. Com objetivo de explicar os fenômenos do homem a partir de uma perspectiva coletiva sem perder de vista a sua individualidade, tendo como função tornar o extraordinário em ordinário.

\subsection{A Teoria das RS, professores e a avaliação da Educação Básica}

De acordo com Jacques (2001, p. 31) a teoria das representações sociais é um importante método de estudo, pois " [...] tem a capacidade de descrever, mostrar uma realidade, um fenômeno que existe, do qual muitas vezes não nos damos conta, mas que possui grande poder mobilizador e explicativo".

Portanto, ao estudar a teoria das RS no cenário educacional, abordando o componente pedagógico da avaliação da aprendizagem, é uma tentativa de acessar os modelos que fazem com que as pessoas passam a construir suas opiniões e concepções acerca do assunto a ser investigado, pois possibilitará aos profissionais da educação um olhar atento e crítico, para alguns componentes do processo pedagógico, como: produção do conhecimento, planejamento, metodologias educacionais e a avaliação da aprendizagem, tem se perpetuado ao longo dos tempos.

É sabido que a trajetória da vida escolar, dos atores educacionais, docentes discentes, configura as RS como um fenômeno psicossocial resultantes de comportamentos coletivos, sendo carregada por diferentes representações, que envolvem símbolos, imagens, atitudes e comportamentos. Ou seja, as representações que os professores e os estudantes apresentam, são ao mesmo tempo fruto da sua vivencia e pensamento, bem como, do que vivenciaram em comum com outros indivíduos. Elas descrevem suas ações não de maneira lógica, racional ou cognitiva e sim por razões afetivas, simbólicas e religiosas.

As RS acontecem no cotidiano como em grupos sociais e mídias, é importante ressaltar que a comunicação é fundamental para as RS. Elas se formam na vida diária das pessoas, quando estas discutem e falam de diversos temas que permeiam seu cotidiano, segundo Moscovici (2001, p. 55) estas representações estão presentes nos meios de divulgação, através da comunicação, nos costumes e instituições, na herança histórica cultural das sociedades.

Como são formas simbólicas podem ser ideológicas, ou seja, podem criar ou reproduzir relações de dominação em contextos específicos. Podem reproduzir relações de 
poder. Então, as RS não são neutras, elas possuem uma função na comunidade que estão inseridas.

Portanto, ao olhar a avaliação pelo viés das RS permitirá compreender as práticas avaliativas escolares e se estas ainda estão ligadas a um modelo tradicional de educação, que consiste apenas classificar e seriar os estudantes, permite também, compreender quais as RS dos conceitos de avaliação da aprendizagem estão presentes nas situações de ensino dos professores da educação básica e como eles re-significam os conceitos avaliativos no contexto do ensino escolar.

A prática avaliativa trás nos seu bojo um conjunto de concepções e instrumentos que perpassam pelas representações sociais dos docentes da educação, permitindo compreender seus comportamentos e como eles representam seus conceitos de avaliação. Assim as ideias de Moscovici são centradas em situações sociais, políticas, culturais, artísticas ou cientificas e que desafiam um princípio onde a ordem está estabelecida e que acabam por convencer um número suficiente de pessoas, implementando e disseminando com êxito alguns pensamentos majoritários.

Nesse sentido, Moscovici (2001) atribui duas funções para as RS, a convencionalizar e prescrever. Na primeira função, as representações convencionalizam formatando algo, que não condiz com as representações que possui, tentando encaixar em alguma categoria já conhecida ao grupo ou indivíduo. Fazemos essa aproximação com base em categorias e paradigmas prévios a ponto de confirmar as representações já existentes. Para Moscivici (2010, p. 55) nesse processo, a memória prevalece sobre a dedução, o passado sobre o presente a resposta sobre o estímulo e as imagens sobre a realidade. Assim, o professor avalia de acordo com o seu modelo pré-estabelecido, buscando modelos de avaliação pelos quais já passou.

A segunda função da representação, a prescrição, e envolve a memória coletiva e suas próprias representações construídas dentro de uma sequência de elaborações e mudanças, e são consideradas por Moscovici (2001, p. 37) como resultado de sucessivas gerações. Desse modo, todas as ideias e experiências que possuímos no presente são determinadas de antemão, ou seja, são prescritas por um passado que acaba por se infiltrar. Portanto, o caráter convencional e prescritivo das representações faz com que elas pareçam naturais, dando a impressão que as representações não foram criadas por algum grupo/indivíduo em determinado momento histórico, mas como algo que sempre existiu. Isso se dá, segundo Moscovici (2001), porque cada RS possui vida e, a partir do momento de sua criação, prossegue caminhos diversos, onde tem a possibilidade de modificar-se, transformar-se ou desaparecer, elas tornam-se independentes de seus criadores distanciando-se de sua origem. 
Para o autor (2001, p. 41) quanto mais sua origem é esquecida e sua natureza convencional é ignorada, mais fossilizada ela se torna.

Para Moscovici (2001) o conhecimento é adquirido por meio da compreensão alcançada por indivíduos que pensam, porém não sozinhos, pois a semelhança de pronunciamentos feitos pelos indivíduos de um grupo demonstra que pensaram juntos sobre os mesmos assuntos, assim a RS é construída no cotidiano de cada indivíduo e a teoria das RS tenta entender as lutas, as batalhas, espaços e formas de comunicações destes indivíduos e a produção de saberes no cotidiano. Assim sendo, Moscovici (2001, p. 56) afirma que:

\begin{abstract}
A RS não pode ser pensada como algo estanque, ou seja, algo terminado, acabado, engessado. Ela nos obriga a pensar, pois exige muito trabalho de interpretação reinterpretação, ela levanta dicotomias, conflitos, deixa-nos diante do desconhecimento. Favorece o crescimento e a busca incessante em torno de descobertas.
\end{abstract}

Em vista disso, a teoria da representação social mostra como as pessoas veem o mundo a sua volta. Portanto a prática avaliativa dos professores é orientada por um conjunto de concepções e instrumentos já estabelecidos pelas experiências anteriores e estes instrumentos são a objetivação das RS da Avaliação como: provas, notas, conceitos, fracasso, sucesso, etc.

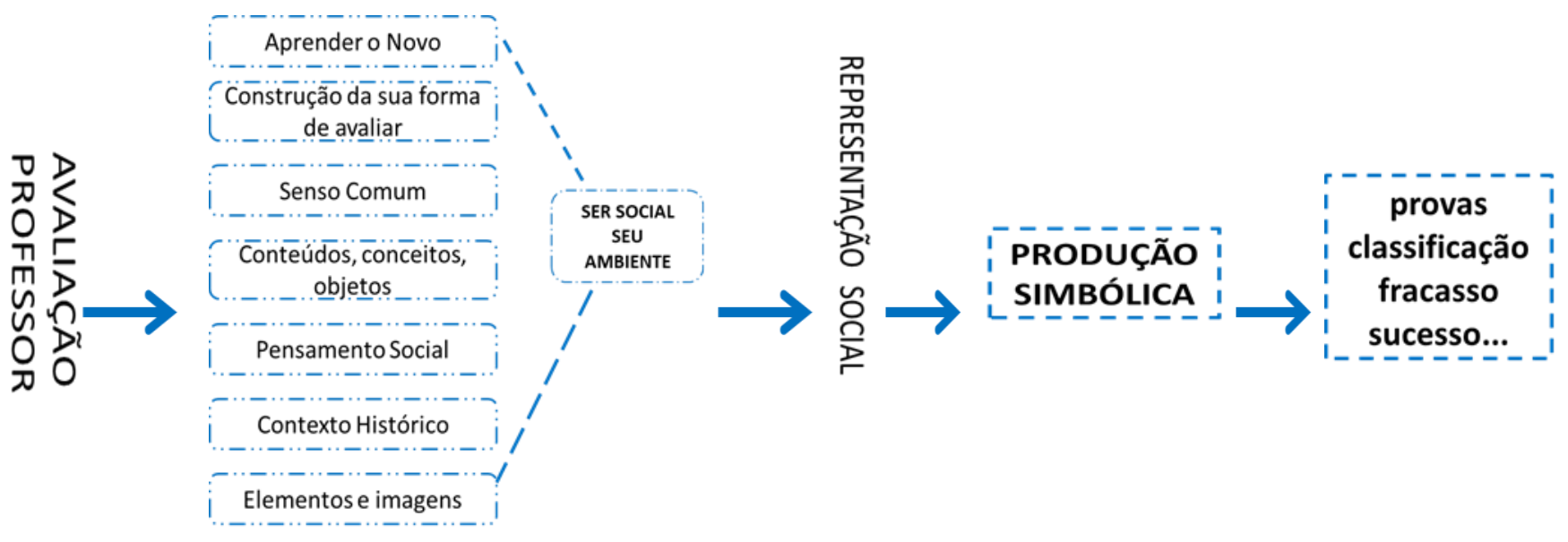

Figura 1 - Relação das Representações Sociais e Avaliação

Considerando que a prática avaliativa é orientada por um conjunto de concepções e instrumentos representativos dos sujeitos envolvidos no processo, intencionamos compreender a avaliação como um fenômeno de representação social.

Nesta lógica, Rocha (2001, p. 32) afirma que,

os fenômenos da representação social estão espalhados nas ideias e práticas individuais e coletivas. Eles são difusos, em constante movimento e presentes em inúmeras instâncias de interação social. São formas de conhecimento, são teorias sobre a realidade. Participar desse universo como indivíduos comuns é uma coisa, estudá-lo como tema substantivo numa investigação científica é outra coisa. 
Sabe-se que com a prática dos exames escolares, a partir dos séculos XVI e XVII, manifestaram-se as concepções dominantes sobre avaliação educacional, segundo Chueiri (2007) estão vinculadas às concepções pedagógicas da educação tradicional e da tecnicista. A concepção tradicional de educação reduz o processo avaliativo à aplicação de provas e exames escolares. Já a tecnicista, evidencia a avaliação como instrumento de medida. Ambas restringem a avaliação como um simples instrumento de classificação e regulação do desempenho do aluno. Inclusive, existem comportamentos pré-estabelecidos social e coletivamente que definem a avaliação como o fim do processo, relacionado, principalmente, ao instrumento avaliativo da prova, com a intenção de aprovar ou reprovar os alunos. Logo, destas concepções decorre a representação de que a avaliação realizada nas escolas visa unicamente emitir notas ou conceitos, com objetivo de classificar e seriar os alunos.

Porém o processo avaliativo vem passando por mudanças e transformações ao longo do tempo, para Chueiri (2007) tanto do ponto de vista epistemológico quanto metodológico, com a intenção de ultrapassar as concepções tradicionais de avaliação, como a avaliação formativa, mediadora e diagnóstica, que vêm à avaliação como um processo, voltado para a análise dos aspectos da aprendizagem dos sujeitos.

Portanto, as mudanças epistemológicas contribuíram para as transformações nas práticas avaliativas das escolas e foram permeadas por diferentes concepções de avaliação educacional, desde a quantitativa até a qualitativa. Como afirma Chueiri (2007, p. 188) o nosso pressuposto de que uma concepção de avaliação no âmbito escolar pode ser considerada um objeto de ruptura tanto do ponto de vista conceitual quanto metodológico.

Considerando a avaliação escolar como um objeto de ruptura e, mencionando à ideia de Moscovici (2004), de que a finalidade de todas as representações sociais é tornar familiar algo não-familiar ou a própria familiaridade, percebemos possibilidades de produção de outras compreensões sobre avaliação no contexto escolar, a partir das representações sociais. Costa (1998) também entende que a avaliação realizada na escola pode ser um artigo de representação social, dado que ela implica a intersubjetividade, ou seja, inclui atores sociais que estão intimamente inter-relacionados em sua prática e que geram uma compreensão compartilhada da realidade.

\section{Considerações Finais}

O presente trabalho tenta ressaltar que a avaliação deve contemplar uma concepção mais ampla, uma vez que envolve formação de juízos e apreciação de aspectos qualitativos 
devendo ser compreendida como uma ação reflexiva do processo da aprendizagem. Como reforça Perrenoud (1999) as práticas de avaliação realizadas no cotidiano das escolas geram resultados cruéis de reprodução das desigualdades sociais, como uma ação a serviço da seleção e da classificação, ignorando e desconsiderando as experiências de vida dos alunos, condenando-os a um silêncio imutável.

Assim sendo, acreditamos que a avaliação da aprendizagem deve ser vista também como prática de investigação e como alternativa às propostas excludentes, que imperam no sistema escolar. Avaliar não se resume apenas em constatar, mas, sobretudo analisar, interpretar, tomar decisões e reorganizar a aprendizagem.

Desta maneira, avaliação é percebida como um procedimento auxiliar que o professor poderá utilizar para detectar os diferentes níveis de aprendizagem e trabalhar a partir destes níveis. Por conseguinte, temos como desafio promover uma avaliação em síntese, que se projeta e vislumbra o futuro, que tem por finalidade a evolução da aprendizagem dos educandos.

Assim sendo, para a avaliação da aprendizagem escolar torna-se efetiva ela não pode fazer uma observação temporária dos desempenhos apresentados pelos alunos, mas, sim apresentar-se de forma constante. Efetivando a prática avaliativa numa perspectiva de futuro acompanhando de perto etapa por etapa do processo tentando contribuir sempre para aprendizagem do aluno.

Por fim, buscar conhecer o modo como um grupo de professores, constrói seus saberes, em relação aos aspectos pedagógicos da sua prática docente permite identificar quais saberes que essa população possui, como é que esses saberes foram construídos nas relações interpessoais em cada momento histórico e quais são os códigos e as regras culturais desta comunidade. As RS problematizam os fenômenos que nos parecem naturalizados. Estuda-la permite compreender e identificar como ela atua na motivação dos professores ao fazer uma escolha para avaliar o estudante. Ao olhar a avaliação pelo viés das RS permitirá compreender as práticas avaliativas escolares e se estas ainda estão ligadas a um modelo tradicional de educação, que consiste apenas classificar e seriar os estudantes, permite também, compreender quais as RS dos conceitos de avaliação da aprendizagem estão presentes nas situações de ensino dos professores da educação básica e como eles re-significam os conceitos avaliativos no contexto do ensino escolar. 


\section{Referências}

ABRIC, J-C. Pratiques sociales et représentations. Paris: Presses Universitaires de France, 1994 a.

ABRIC, Jean-Claude. O estudo experimental das representações sociais. In D Jodelet (org.). As representações sociais. Rio de Janeiro: Editora UERJ, 2000.

BARRETO, F.S. Sobre as representações Sociais e o tempo histórico. Revista Lâmina. n. $1 /$ set $/ 2005$.

CHUEIRI, M. S. F. Concepções sobre a Avaliação Escolar. Estudos em Avaliação Educacional, v. 19, n. 39, jan./abr. 2007.

COSTA, W.A.da \& ALMEIDA, A.M.O. Teoria das Representações Sociais: uma abordagem alternativa para se compreender o comportamento cotidiano dos indivíduos e dos grupos sociais. Rev.Educ.Pública v.8.n.13, jan - jun.UFMT. 1999.

FALCON, F.J. C História e Representação. In: CARDOSO, C.F.; MALERBA, J. (Orgs.) REPRESENTAÇOES: Contribuição a um debate transdisciplinar. Campinas, SP: Papirus, 2000 (coleção textos do tempo) p.20-48.

FARR, R. M. Representações sociais: a teoria e sua história. In: GUARESCHI, P.; JOVCHELOVITCH, S. (Org.). Texto em representações sociais. 2. ed. Petrópolis: Vozes, 1995. p. 31-59.

GADOTTI, M. Perspectivas atuais da educação. Porto Alegre, Ed. Artes Médicas, 2012.

JACQUES, Maria da Graça Corrêa. Psicologia social contemporânea. Livro texto. 5. Ed. Petrópolis: Vozes, 2001.

JODELET, D. Representações sociais: um domínio em expansão. In: JODELET, D. (org.) Representações Sociais. Rio de Janeiro: EDUERJ. 2001.17-44p

JOVCHELOVITCH, S. Representações Sociais: para uma fenomenologia dos saberes sociais - Psicologia \& Sociedade 10(1) jan./jun.1998. p.54-68.

LIMA, L. C. A escola como organização educativa. Uma abordagem sociológica. 3 ed. São Paulo: Cortez , 2008.

MARTINI, J.G. As Representações Sociais: teorias e práticas. Ciências Sociais Unisinos. v.37.n.158. jan./jun.2001.

MAZZOTTI-ALVES, A. J. Representações Sociais: aspectos teóricos e aplicações à Educação. Revista Múltiplas Leituras, v.1, n. 1, p. 18-43, jan. / jun. 2008.

MELCHIOR, M. C. Avaliação na concepção dos professores. In: Avaliação Pedagógica:função e necessidade. Porto Alegre: Mercado Aberto, 1994, p. 29-55. 
MINAYO, M.C.S. O conceito de Representações Sociais dentro da Sociologia Clássica. In: - GUARESCHI, P; JOVCHELOVITCH, S. (Orgs); Texto em Representações Sociais $2^{\mathrm{a}}$ ed. - Petrópolis/RJ: Vozes, 1995.

MOSCOVICI, S. Representações sociais: investigações em psicologia social. $2^{\mathrm{a}} \mathrm{ed}$. Petrópolis: Vozes, 2001.

PERRENOUD, P. Avaliação: da excelência à regulação das aprendizagens - entre duas lógicas. Porto Alegre: Artes Médicas, 1999.

Queiroz, MS. Representações sociais: uma perspectiva multidisciplinar em pesquisa qualitativa. In RB Barata \& R Briceño-León (org.). Doenças endêmicas: abordagens culturais e comportamento, Rio de Janeiro: Fiocruz, 2000.

REIS, S L A e BELLINI, M. Revista Acta Scientiarum. Human and Social Sciences Maringá, v. 33, n. 2, p. 149-159, 2011.

ROCHA, M. I. A., RIBEIRO, L. P. História, abordagens, métodos e perspectivas da Teoria das Representações Sociais. Psicologia e sociedade. N.2. Minas Gerais, 2016, p. 407-409.

SILVA, J. P; URT, S. C. Educação infantil e avaliação: uma ação mediadora. Nuances: estudos sobre Educação. Presidente Prudente: v. 25, n. 3, p. 56-78, set./dez. 2002.

TARDIF, M. LESSARD, C. GAUTHIER, C. Formação dos professores e contextos sociais. Porto: Rés, 2001.

ZABALA, A. A prática educativa: como ensinar. Porto Alegre: Artmed, 1998. 